University of Nebraska - Lincoln

DigitalCommons@University of Nebraska - Lincoln

April 1995

\title{
Effect of Accounting for Different Phenotypic Variances by Sire Breed and Sex on Selection of Sires Based on Expected Progeny Differences for 200- and 365-Day Weights
}

\author{
F. A. Rodriguez-Almeida \\ University of Nebraska-Lincoln \\ L. Dale Van Vleck \\ University of Nebraska-Lincoln, dvan-vleck1@unl.edu \\ Larry V. Cundiff \\ University of Nebraska-Lincoln, Icundiff2@unl.edu
}

Follow this and additional works at: https://digitalcommons.unl.edu/animalscifacpub

Part of the Animal Sciences Commons

Rodriguez-Almeida, F. A.; Van Vleck, L. Dale; and Cundiff, Larry V., "Effect of Accounting for Different Phenotypic Variances by Sire Breed and Sex on Selection of Sires Based on Expected Progeny Differences for 200- and 365-Day Weights" (1995). Faculty Papers and Publications in Animal Science. 256.

https://digitalcommons.unl.edu/animalscifacpub/256

This Article is brought to you for free and open access by the Animal Science Department at DigitalCommons@University of Nebraska - Lincoln. It has been accepted for inclusion in Faculty Papers and Publications in Animal Science by an authorized administrator of DigitalCommons@University of Nebraska - Lincoln. 


\title{
Effect of Accounting for Different Phenotypic Variances by Sire Breed and Sex on Selection of Sires Based on Expected Progeny Differences for 200- and 365-Day Weights ${ }^{1,2}$
}

\author{
F. A. Rodríguez-Almeida ${ }^{*, 3}$, L. D. Van Vleck*,†, and L. V. Cundiff ${ }^{*}$ \\ *Department of Animal Science, University of Nebraska, Lincoln 68583-0908 and \\ ${ }^{\dagger}$ Roman L. Hruska U.S. Meat Animal Research Center, ARS, USDA, Clay Center, NE 68933
}

\begin{abstract}
The effects of accounting for different phenotypic variances according to sire breed and sex subclasses on estimation of sire breed effects and prediction of expected progeny differences of sires mated to Hereford and Angus cows were investigated. Data consisted of 6,977 and 6,530 records of 200-d (weaning) and 365-d (yearling) weights, respectively, of $F_{1}$ calves sired by bulls ( 662 and 661 , respectively) of 23 breeds that have been evaluated in the Germ Plasm Evaluation Program at the U.S. Meat Animal Research Center, Clay Center, NE. Models compared included fixed effects of genetic group of sire (samples of sires evaluated at different times), dam breed, sex, birth year of calf and age of dam, plus sire within genetic group and dam within dam breed as random effects. Variance structures were different: Model I assumed homogeneous variances across sire breed-sex subclasses; Model II accounted for differences in phenotypic variance by sire breed and sex subclasses. Differences between estimates of sire
\end{abstract}

group effects obtained with the two models were not significant for either trait. Product-moment and rank correlations between expected progeny differences obtained with Model I and Model II were greater than .93 when computed within each group and .99 or larger when computed across breeds. There were slight changes in the numbers of sires contributed by different breeds to the proportions selected across breeds under different selection intensities when sires were ranked with the two models. However, differences between means predicted under Model II were small when sires were ranked and selected based on the two models. Changes in standard errors of prediction for expected progeny differences and standard errors for estimates of breed effects obtained when adjusting for differences of phenotypic variances, compared to not adjusting, were proportional to the ratios of the phenotypic standard deviations of the sire breeds to the common phenotypic standard deviation.

Key Words: Expected Progeny Difference, Multiple Breeds, Beef Cattle

J. Anim. Sci. 1995. 73:2589-2599

\section{Introduction}

Heterogeneity of variance for weight traits in multibreed populations of beef cattle has been associated with breed composition and sex (Garrick et al., 1989; Núñez-Domínguez et al., 1995; RodríguezAlmeida et al., 1995). Some procedures have been proposed to account for differences in variances of

\footnotetext{
${ }^{1}$ Published as paper no. 10902, Journal Ser., Nebraska Agric. Res. Div., Univ. of Nebraska, Lincoln 68583-0908.

${ }^{2}$ This study was conducted while the first author was a graduate student with financial support of Consejo Nacional de Tecnologia (CONACYT) and Universidad Autónoma de Chihuahua, México.

${ }^{3}$ Current address: Facultad de Zootecnia, UACH. Apdo. Postal 4-28, Chihuahua, Mexico C.P. 31031.

Received October 5, 1994.

Accepted April 28, 1995.
}

traits measured on animals classified into different subclasses (e.g., Henderson, 1984; Hill, 1984; Gianola, 1986; Quaas et al., 1989; Elzo, 1989; Kachman and Everett, 1993). The complexity of these procedures depends on the degree of relaxation of the assumptions made with respect to the variance-covariance structures involved in the models generally used for genetic evaluations. Garrick et al. (1989) and Rodríguez-Almeida et al. (1995) found correlations between expression of genetic effects in different sexes to be close to unity for weight traits of beef cattle. Taking advantage of this fact, Quaas et al. (1989) proposed a simplified approach to account for heterogeneous variances in models for genetic evaluations of beef cattle. This approach gives equivalent results to the ones obtained with a procedure presented by Henderson (1984) for a sire model that treats measurements in different herds as different traits 
Table 1. Distribution of 23 sire breeds used in the Germ Plasm Evaluation Program through five cycles

\begin{tabular}{lllll}
\hline \hline $\begin{array}{l}\text { Cycle I } \\
(1970-72)\end{array}$ & $\begin{array}{c}\text { Cycle II } \\
(1973-74)\end{array}$ & $\begin{array}{c}\text { Cycle III } \\
(1975-76)\end{array}$ & $\begin{array}{c}\text { Cycle IV } \\
(1986-90)\end{array}$ \\
\hline Hereford 1 & Hereford 1 & Hereford 1 & Hereford 1\&2 & Hereford 2 \\
Poll Hereford 1 & Poll Hereford 1 & Poll Hereford 1 & Poll Hereford 1\&2 & Poll Hereford 2 \\
Angus 1 & Angus 1 & Angus 1 & Angus 1\&2 & Bngus 2 \\
Jersey & Red Poll & Brahman & Songhorn & Piedmontese \\
South Devon & Brown Swiss & Sahiwal & Galloway & Nellore \\
Limousin & Gelbvieh 1 & Pinzgauer 1 & Shorthorn \\
Simmental & Maine-Anjou & Tarentaise & Piedmontese \\
Charolais 1 & Chianina & & Charolais 2 \\
& & & Gelbvieh 2 \\
& & & Pinzgauer 2 \\
\hline
\end{tabular}

${ }^{\mathrm{a}}$ Groups 1 and 2 within the same breed represent samples of sires introduced at different cycles of the Germ Plasm Evaluation Program.

with the assumption that variance components as fractions of the phenotypic variance are the same across herds, and that correlations between expressions of sire effects in different herds are unity. Henderson's (1984) procedure uses a generalized inverse of the variance-covariance matrix for sire effects to build the mixed-model equations.

In a previous study, Rodríguez-Almeida et al. (1995) failed to find any significant differences in variance explained by sire and dam models including different variance components as fractions of the phenotypic variance compared to models accounting for differences in phenotypic variances only, with sire and dam variances as fractions of the phenotypic variance being equal across sire breed, dam breed and sex subclasses. Thus, the objective of the present study was to implement the procedure proposed by Quaas et al. (1989) to investigate the effect of accounting for different phenotypic variances of 200- and 365-d weights according to sire breed and sex on prediction of EPD of sires mated to Hereford and Angus cows.

\section{Materials and Methods}

Description of Data. Data consisted of 6,977 and 6,530 records of 200-d (WW) and 365-d (YW) weights, respectively, of calves from Hereford $(\mathbf{H})$ and Angus ( A) cows and sired by bulls of 23 of the breeds that have been evaluated in the Germ Plasm Evaluation (GPE) program at the Roman L. Hruska U. S. Meat Animal Research Center, Clay Center, NE.

The GPE program has been conducted in five cycles. Table 1 shows the distribution of the 23 sire breeds considered in the present study through the different cycles. The same Hereford and Angus bulls were used by artificial insemination in all cycles to create ties for breed comparisons. In addition, new samples of $\mathrm{H}, \mathrm{A}$, Polled Hereford, Charolais, Pinzgauer, and Gelbvieh bulls were introduced in Cycle IV to evaluate genetic trend in these breeds. The first sample of sires for each breed was identified as group 1 and the sample introduced later as group 2 . The original data set included a few sires that were more than $87 \%$ Gelbvieh or Pinzgauer that were classified into the purebred Gelbvieh and Pinzgauer groups. Foundation cows were purchased as calves at weaning from commercial producers in Nebraska; thus, pedigree information was not available for them.

Records from purebred $\mathrm{H}$ and $\mathrm{A}$ were eliminated from the analyses so that all sire breed effects were confounded with heterosis effects. Only data from males castrated at birth and female calves were considered. Records from bull calves, late castrated males, and freemartin and ovariectomized heifers were deleted from the original data set. Table 2 shows the distribution of records by sire genetic group and sex and the number of sires for each sire genetic group.

A general description of management was given by Rodríguez-Almeida et al. (1995). Calves were born in the spring, males were castrated within $24 \mathrm{~h}$, and all calves were creep-fed whole oats from mid-July until weaning in late October. For the first three cycles, calves were weaned at approximately $200 \mathrm{~d}$ of age. Because of drought, calves born in 1974 were weaned early at an average of $167 \mathrm{~d}$. In later cycles, weaning age averaged $170 \mathrm{~d}$. After weaning, heifers were managed to calve first at $2 \mathrm{yr}$ of age and were fed a diet, according to their stage of growth, of approximately $50 \%$ corn silage and $50 \%$ alfalfa or grass haylage, on a dry matter basis, plus protein and mineral supplement. After weaning, steers received a high energy density diet for approximately $196 \mathrm{~d}$ for the first three cycles and for an average of $230 \mathrm{~d}$ for later cycles, after a preconditioning period of 25 to 58 d.

The Model. In a previous study with these data (Rodriguez-Almeida et al., 1995), the nature of the heterogeneity of variance due to sire breed, sex, and dam breed was investigated with the result that 
Table 2. Numbers of sires and records for 200- and 365-day weights of calves from 23 sire breeds

\begin{tabular}{|c|c|c|c|c|c|}
\hline \multirow[b]{2}{*}{ Sire breed } & \multirow[b]{2}{*}{ Sires } & \multicolumn{2}{|c|}{ 200-d weight } & \multicolumn{2}{|c|}{ 365-d weight } \\
\hline & & Males & Females & Males & Females \\
\hline Hereford 1 & 28 & 267 & 224 & 263 & 174 \\
\hline Hereford 2 & 22 & 41 & 40 & 40 & 40 \\
\hline Poll Hereford 1 & 5 & 69 & 71 & 67 & 60 \\
\hline Poll Hereford 2 & 21 & 24 & 36 & 22 & 36 \\
\hline Angus 1 & 35 & 265 & 211 & 265 & 174 \\
\hline Angus 2 & $53^{\mathrm{a}}$ & 66 & 75 & 63 & 74 \\
\hline Charolais 1 & 26 & 179 & 161 & 175 & 128 \\
\hline Charolais 2 & 38 & 103 & 85 & 102 & 85 \\
\hline Gelbvieh 1 & 11 & 109 & 84 & 108 & 83 \\
\hline Gelbvieh 2 & 18 & 112 & 104 & 112 & 103 \\
\hline Pinzgauer 1 & 9 & 179 & 174 & 177 & 113 \\
\hline Pinzgauer 2 & 16 & 103 & 102 & 100 & 99 \\
\hline Simmental & 27 & 177 & 189 & 174 & 156 \\
\hline Limousin & 20 & 176 & 162 & 173 & 161 \\
\hline Brahman & 34 & 177 & 207 & 174 & 142 \\
\hline Brown Swiss & 11 & 118 & 133 & 117 & 133 \\
\hline Chianina & 20 & 119 & 97 & 119 & 97 \\
\hline Galloway & 30 & 86 & 77 & 85 & 76 \\
\hline Jersey & 33 & 131 & 144 & 131 & 114 \\
\hline Longhorn & 28 & 104 & 83 & 104 & 83 \\
\hline Maine-Anjou & 18 & 107 & 90 & 107 & 89 \\
\hline Nelore & 22 & 103 & 83 & 102 & 82 \\
\hline Piedmontese & 29 & 127 & 133 & 120 & 132 \\
\hline Red Poll & 16 & 112 & 94 & 110 & 94 \\
\hline Sahiwal & 6 & 156 & 150 & 155 & 86 \\
\hline South Devon & 27 & 96 & 118 & 96 & 118 \\
\hline Shorthorn & 25 & 98 & 75 & 98 & 73 \\
\hline Salers & 27 & 89 & 91 & 87 & 90 \\
\hline Tarentaise & 7 & 105 & 86 & 104 & 85 \\
\hline Total & $662^{a}$ & 3,598 & 3,379 & 3,550 & 2,980 \\
\hline
\end{tabular}

aThese numbers correspond to number of sires for 200 -d weight, but there was one less sire for 365-d weight.

variance components for WW and YW differed $(P<$ .05 ) in scale according to sire breed and sex subclasses. Thus, two sire and dam models were used to analyze the data. With the first model (Model I), the variances were assumed to be equal by sire breed and sex subclasses. A second model (Model II) accounted for differences in the scale of the variances (i.e., phenotypic variances $\left(\sigma_{\mathrm{p}}^{2}\right)$ were considered to be different for each sire breed-sex subclass, even though sire and dam variance components as fractions of the $\sigma_{\mathrm{p}}^{2}$ were assumed equal for all sire breeds and sexes).

The general structure for the two models was similar and can be represented as follows:

$$
\mathbf{y}=\mathbf{X} \boldsymbol{\beta}+\mathbf{Z s}+\mathbf{W d}+\mathbf{e}
$$

where $\mathbf{y}$ is the vector of observations (i.e., WW or $\mathrm{YW}) ; \boldsymbol{\beta}$ is the vector of fixed effects that includes effects due to genetic group of sire, dam breed, sex, birth year of calf, and age of dam $(2,3,4$ and $>4 \mathrm{yr}) ; \mathbf{s}$ is a vector of random sire within genetic group of sire effects; $\mathbf{d}$ is a vector of random dam within dam breed effects; $\mathbf{e}$ is a vector of residuals; $\mathbf{X}$ is an incidence matrix with zeros and ones relating observations to the fixed effects; and $\mathbf{Z}$ and $\mathbf{W}$ are incidence matrices relating observations to the sire and dam effects, respectively. These matrices are different for the two models. For the common variances model (Model I) these matrices consist of zeros and ones, but for Model II the ones are replaced by ratios $\left(\lambda_{i j}\right)$ of the phenotypic standard deviation for the ijth sire breedsex subclass corresponding to a specific observation to the common phenotypic standard deviation for all sire breed-sex subclasses, as explained later.

First and second moments of the models are:

$$
\mathbf{E}\left[\begin{array}{c}
\mathbf{y} \\
\mathbf{s} \\
\mathbf{d} \\
\mathbf{e}
\end{array}\right]=\left[\begin{array}{c}
\mathbf{X} \beta \\
0 \\
0 \\
0
\end{array}\right] ; \operatorname{Var}\left[\begin{array}{c}
\mathbf{y} \\
\mathbf{s} \\
\mathbf{d} \\
\mathbf{e}
\end{array}\right]=\left[\begin{array}{cccc}
\mathbf{V} & \mathbf{Z} \boldsymbol{\sigma}_{\mathrm{s}}^{2} & \mathbf{W} \boldsymbol{\sigma}_{\mathrm{d}}^{2} & \mathbf{R} \\
\mathbf{Z}^{\prime} \boldsymbol{\sigma}_{\mathrm{s}}^{2} & \mathbf{I}_{\mathrm{n}_{\mathrm{s}}} \boldsymbol{\sigma}_{\mathrm{s}}^{2} & 0 & 0 \\
\mathbf{W}^{\prime} \boldsymbol{\sigma}_{\mathrm{d}}^{2} & 0 & \mathbf{I}_{\mathrm{n}_{\mathrm{d}}} \boldsymbol{\sigma}_{\mathrm{d}}^{2} & 0 \\
\mathbf{R} & 0 & 0 & \mathbf{R}
\end{array}\right]
$$

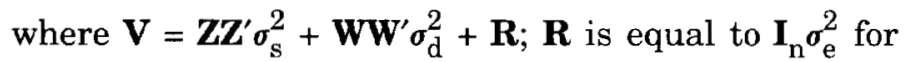
Model I. For Model II the identity matrix is replaced by a diagonal matrix with elements consisting of 
scaling factors $\lambda_{\mathrm{ij}}$ corresponding to observations in the ijth sire breed-sex subclass. $\sigma_{\mathrm{s}}^{2}, \sigma_{\mathrm{d}}^{2}$, and $\sigma_{\mathrm{e}}^{2}$ are variances due to sire, dam and residual random effects, respectively. Numbers of sires, dams, and total observations are $n_{s}, n_{d}$, and $n$, respectively.

Accounting for differences in variances as with Model II was first proposed by Quaas et al. (1989). Examination of the contributions of the different variance components to the variance of $\mathbf{y}$ (i.e., $\mathbf{V}=\mathbf{Z Z}$ $\left.\boldsymbol{\sigma}_{\mathrm{s}}^{2}+\mathbf{W W}^{\prime} \boldsymbol{\sigma}_{\mathrm{d}}^{2}+\mathbf{R}\right)$ shows that the contributions to the variance of an observation in the $i^{\text {th }}$ sire breed-sex sublcass are as follows:

$\lambda_{\mathrm{ij}}^{2} \sigma_{\mathrm{s}}^{2}+\lambda_{\mathrm{ij}}^{2} \sigma_{\mathrm{d}}^{2}+\lambda_{\mathrm{ij}}^{2} \sigma_{\mathrm{e}}^{2}=\lambda_{\mathrm{ij}}^{2}\left(\sigma_{\mathrm{s}}^{2}+\sigma_{\mathrm{d}}^{2}+\sigma_{\mathrm{e}}^{2}\right)=\lambda_{\mathrm{ij}}^{2} \sigma_{\mathrm{p}}^{2}$,

where $\sigma_{\mathrm{p}}^{2}$ is the average phenotypic variance for all sire breed-sex subclasses. The covariance between two observations with a common random effect (i.e., weights of calves from the same sire or from the same dam) is $\lambda_{\mathrm{ij}} \lambda_{\mathrm{i}^{\prime} j^{\prime}} \sigma_{\mathrm{s}}^{2}$ or $\lambda_{\mathrm{ij}} \lambda_{\mathrm{i}^{\prime} j^{\prime}} \sigma_{\mathrm{d}}^{2}$. This model requires correlations between random effects expressed on calves in different subclasses to be unity, which according to previous results (Rodríguez-Almeida et al., 1995) seems to be a reasonable assumption.

To account for differences in scale of phenotypic variances for dairy cattle traits according to herd or herd-year-season subclasses, some authors (Hill, 1984; Brotherstone and Hill, 1986; Wiggans and VanRaden, 1991; Kachman and Everett, 1993; Koots et al., 1994) have recommended that observations be weighted by the phenotypic standard deviation within a subclass. That approach has a scaling effect on estimates of fixed effects, so it is only adequate when fixed effects are nested within subclasses with the differences in variances. For the present situation, main effects of sire breed and sex were included in the model, but the interaction between them was not considered. Conversely, phenotypic variances were considered to be different for each sire breed-sex subclass. Expected progeny differences are functions of the sire genetic group fixed effects as well as of the random sire effects, so it is important to maintain estimates of the fixed effects on the original scale because that is a characteristic of the breed. Differences in sex frequencies for two sire genetic groups could change the sign of the estimated difference between their means if observations were scaled by phenotypic standard deviations within sex. It would not be possible to transform this difference back to the original scale by rescaling the estimates of the sire genetic group effects.

Henderson (1984) and Gianola (1986) proposed that measurements in subclasses with different variances be treated as different traits to account for heterogeneity of variance. This approach increases the number of equations to solve and number of parameters to estimate by a proportion equal to the number of subclasses with different variances. The procedure used with Model II takes into account differences in phenotypic variances without changing the scale of estimates of the fixed effects and without increasing the number of equations to solve and parameters to estimate, other than phenotypic variances. With this last approach different ratios of standard deviations ( $\left.\lambda^{\prime} s\right)$ for the different random effects in the model can be used when variance components differ not only in scale but also as fractions of the phenotypic variance. This approach was described by Quaas et al. (1989); however, as they indicated, this procedure requires any correlation between random effects in the model to be the same from one subclass to another (e.g., for an animal model including the covariance between additive direct and additive maternal genetic effects, the correlation between those two effects must be the same across subclasses with different variances).

\section{Expected Progeny Differences}

Predictions of EPD were obtained with the series of computer programs, MTDFREML, developed by Boldman et al. (1993). The programs were modified to implement prediction of EPD described for Model II. Variance component estimates as fractions of $\sigma_{\mathrm{p}}^{2}$ used for these analyses were obtained from data used by Rodríguez-Almeida et al. (1995): .06 and .11 for sire components and .39 and .24 for dam components on WW and YW, respectively.

Model $I$. To solve the mixed-model equations (MME) the solution corresponding to the Angus 1 sire genetic group was constrained to zero; therefore, all solutions for the sire breed groups were estimates of differences from the one with the zero constraint (Angus 1). Expected progeny differences of sires were calculated as the sum of the solution from the MME for the genetic group of sire effect and the solution for the random effect of the sire.

Model II. Solutions for sire and dam effects obtained by solving the MME corresponding to Model II are predictions of these effects for a sire breed-sex subclass with average variance. Henderson (1984) indicated that to predict the value of a random effect for a subclass with different variance it is necessary to rescale the solutions to the original scale by multiplying by the respective ratio $\lambda_{\mathrm{ij}}$. From a practical point of view, the breed of a sire is known before it is used; however, in most situations it is not possible to know prior to birth the sex of a calf. Therefore, rescaling solutions for sire effects obtained with Model II according to the phenotypic variance of the sire breed is logical, but in the case of sex it is more logical to have the EPD of a sire be the average for both sexes.

Thus, EPD obtained with Model II included the solution for the genetic group of the sire effect, as for 
Table 3. Ratios of the estimated phenotypic standard deviation for each sire breedsex subclass to the common estimate of the phenotypic standard deviation

\begin{tabular}{|c|c|c|c|c|}
\hline \multirow[b]{2}{*}{ Sire breed } & \multicolumn{2}{|c|}{200 -d weight } & \multicolumn{2}{|c|}{ 365-d weight } \\
\hline & Males & Females & Males & Females \\
\hline Hereford ${ }^{a b}$ & .99 & .91 & 1.12 & .89 \\
\hline Angus $^{\mathrm{a}}$ & .99 & 1.08 & .98 & .89 \\
\hline Charolais $^{\mathrm{a}}$ & 1.26 & 1.18 & 1.33 & .99 \\
\hline Gelbvieh $^{\mathrm{a}}$ & 1.14 & 1.17 & 1.14 & 1.02 \\
\hline Pinzgauer ${ }^{\mathrm{a}}$ & 1.20 & .97 & 1.23 & .94 \\
\hline Simmental & 1.05 & .89 & 1.08 & .89 \\
\hline Limousin & 1.06 & .88 & 1.04 & .75 \\
\hline Brahman & .99 & .86 & .98 & .90 \\
\hline Brown Swiss & .92 & .97 & .99 & .90 \\
\hline Chianina & .98 & .93 & 1.08 & .86 \\
\hline Galloway & 1.05 & .87 & 1.04 & .87 \\
\hline Jersey & .78 & .67 & .93 & .71 \\
\hline Longhorn & .90 & .87 & .92 & .78 \\
\hline Maine-Anjou & 1.03 & .95 & 1.01 & .96 \\
\hline Nelore & 1.13 & .99 & 1.10 & .77 \\
\hline Piedmontese & 1.39 & 1.08 & 1.39 & .87 \\
\hline Red Poll & .89 & .93 & .93 & .83 \\
\hline Sahiwal & .91 & .78 & .94 & .88 \\
\hline South Devon & 1.00 & .92 & 1.13 & .89 \\
\hline Shorthorn & 1.07 & 1.23 & 1.21 & .91 \\
\hline Salers & 1.09 & 1.17 & 1.09 & .97 \\
\hline Tarentaise & .90 & .71 & .98 & .65 \\
\hline
\end{tabular}

aPhenotypic variances were estimated in common for the two genetic groups within these sire breeds.

bPhenotypic variances were estimated in common for the Hereford and Polled Hereford sire breeds.

Model I, plus the solution for the random effect of the sire multiplied by the ratio $\left(\lambda_{i}\right)$ of the phenotypic standard deviation for the breed of the sire to the average phenotypic standard deviation for all sire breeds and sexes, as explained later.

Phenotypic Variances. Estimates of phenotypic variances used to calculate scaling factors $\left(\lambda_{\mathrm{ij}}\right.$ and $\left.\lambda_{\mathrm{i}}\right)$ were obtained by fitting different sire and dam models. Variances were assumed to be equal for different genetic groups within a sire breed (i.e., those sire breeds for which two different samples of sires were used in different cycles of the GPE program). Also, variances were estimated in common for the Hereford and Polled Hereford sire breed groups.

Estimates of phenotypic variances for each sire breed-sex subclass were obtained by fitting a two-trait sire and dam model with measurements on the two sexes considered to be different traits. A separate analysis was done for data for each sire breed. Fixed effects included in the model were genetic group of sire, dam breed, birth year of the calf, and age of the dam. A single-trait model was used to obtain pooled estimates of phenotypic variances across sexes for each sire breed. Fixed effects for this model were as before, except each fixed effect was fitted within sex. Dam within dam breed random effects were not considered for data sets other than those for Polled Hereford and Hereford, Angus, Charolais, Simmental, Limousin, Pinzgauer, and Gelbvieh sire breeds, because only few cows had more than one progeny within a sire breed. The same single-trait sire and
Table 4. Ratios of the estimated phenotypic standard deviation for each sire breed to the common estimate of the phenotypic standard deviation

\begin{tabular}{|c|c|c|}
\hline \multirow[b]{2}{*}{ Sire breed } & \multicolumn{2}{|c|}{ Trait } \\
\hline & 200-d weight & 365-d weight \\
\hline Hereford $^{\mathrm{ab}}$ & .95 & 1.03 \\
\hline Angus $^{\mathbf{a}}$ & 1.01 & .94 \\
\hline Charolais $^{\mathrm{a}}$ & 1.22 & 1.19 \\
\hline Gelbvieh $^{\mathrm{a}}$ & $\mathbf{1 . 1 6}$ & 1.08 \\
\hline Pinzgauer $^{a}$ & 1.09 & 1.12 \\
\hline Simmental & .97 & .99 \\
\hline Limousin & .97 & .89 \\
\hline Brahman & .92 & .96 \\
\hline Brown Swiss & .94 & .94 \\
\hline Chianina & .96 & .98 \\
\hline Galloway & .95 & .96 \\
\hline Jersey & .70 & .80 \\
\hline Longhorn & .89 & .86 \\
\hline Maine-Anjou & .99 & .98 \\
\hline Nelore & 1.05 & .94 \\
\hline Piedmontese & 1.24 & 1.14 \\
\hline Red Poll & .89 & .91 \\
\hline Sahiwal & .86 & .93 \\
\hline South Devon & .94 & .99 \\
\hline Shorthorn & 1.11 & 1.10 \\
\hline Salers & 1.13 & 1.03 \\
\hline Tarentaise & .80 & .86 \\
\hline Phenotypic variance ${ }^{c}$ & 489 & 1,072 \\
\hline
\end{tabular}

aPhenotypic variances were estimated in common for the two genetic groups within these sire breeds.

bPhenotypic variances were estimated in common for the Hereford and Polled Hereford sire breeds.

${ }^{\mathrm{c}}$ Phenotypic variance given in kilograms ${ }^{2}$. 


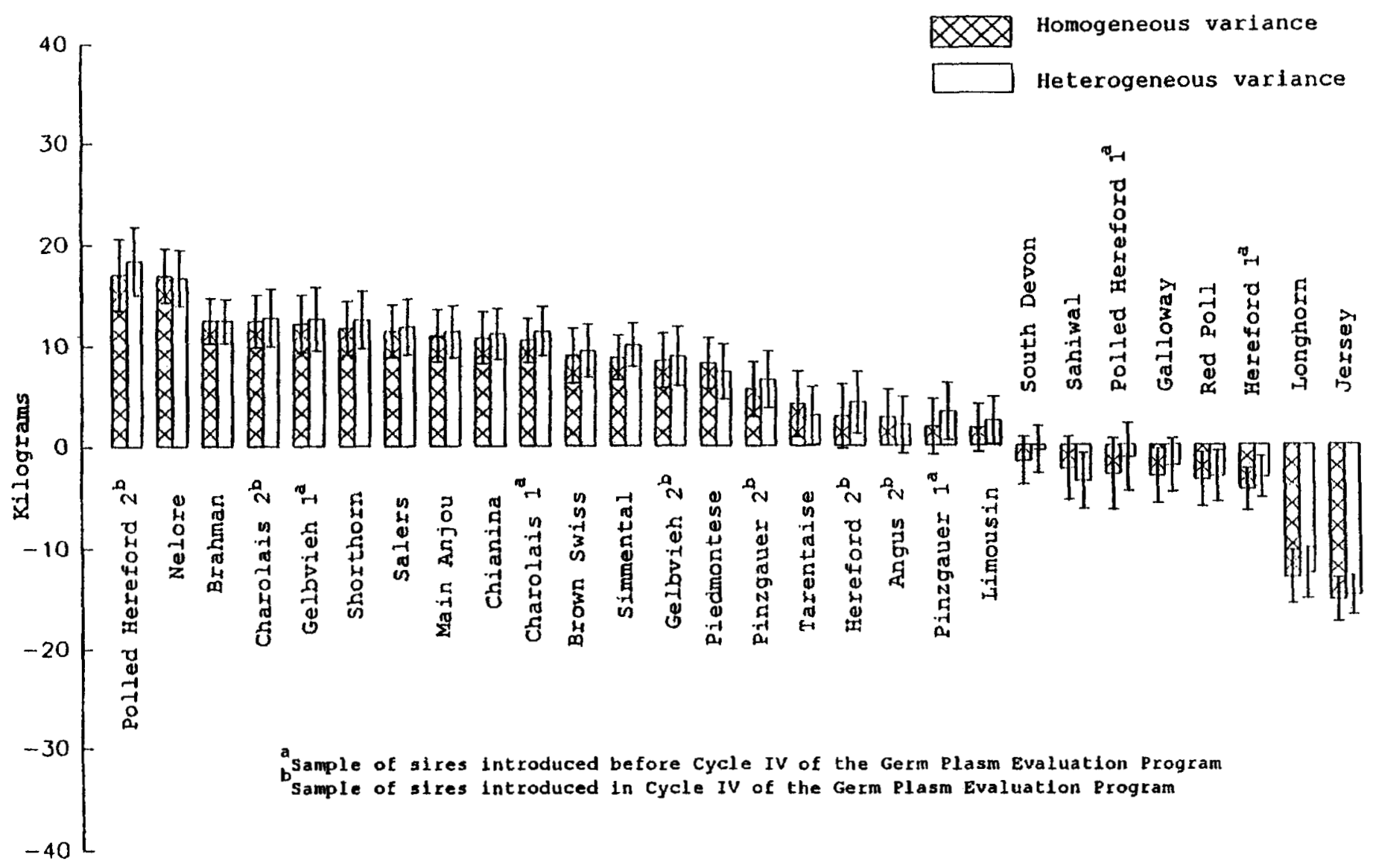

Figure 1. Estimates of breed of sire effects $\left( \pm S E\right.$ ), as deviations from Angus $1^{\mathrm{a}}$, for 200-d weight with models assuming 1) homogeneous or 2) heterogeneous phenotypic variances.

dam model also was used to obtain pooled estimates of the phenotypic variances across all sire breeds and sexes with fixed effects nested within each sire breedsex subclass.

Assessment of Reranking of Sires. To determine the degree of reranking of sires according to EPD obtained with the two different models, product-moment (Pearson) and rank (Spearman) correlations between the two sets of EPD were calculated for each sire breed and across breeds.

To evaluate the impact of reranking of sires ranked based on EPD obtained with the two models, the mean EPD values of the top $20 \%$ of sires for each ranking and the differences between the means for the two sets of rankings were calculated from evaluations under the heterogeneous variances model (Model II) for each sire breed. Mean EPD values from Model II also were obtained for various proportions $(20,15,10$, and $5 \%$ ) of sires selected across breeds.

\section{Results and Discussion}

Phenotypic Variances. Table 3 contains the ratios $\left(\lambda_{i j}\right)$ of the estimated phenotypic standard deviation for each sire breed-sex subclass to the pooled estimate of the phenotypic standard deviation for all sire breeds and sexes. The ranges of these ratios for WW and $\mathrm{YW}$, respectively, are from .67 and .71 for females sired by Jersey bulls to 1.39 and 1.39 for males sired by Piedmontese bulls. In general, differences in estimated phenotypic variances for the two sexes were relatively more pronounced for YW than for WW. Ratios were even slightly larger for WW of females than for WW of males for some of the sire breeds (Gelbvieh, Brown Swiss, Red Poll, Shorthorn, and Salers). Estimates of phenotypic variances for YW were always larger for males than for females.

Ratios $\left(\lambda_{i}\right)$ of the pooled estimates of phenotypic standard deviations across sexes for each sire breed to the pooled estimate across all sire breeds and sexes are presented in Table 4. Differences in estimates of phenotypic variances among sire breeds were relatively larger for WW than for YW. The ratios for WW ranged from .70 for Jersey to 1.24 for Piedmontese. The corresponding ratios for $\mathrm{YW}$ ranged from .80 for Jersey to 1.19 for Charolais. The ranges in these ratios may look smaller than expected, but it should be recalled that these data correspond to $F_{1}$ animals (i.e., 


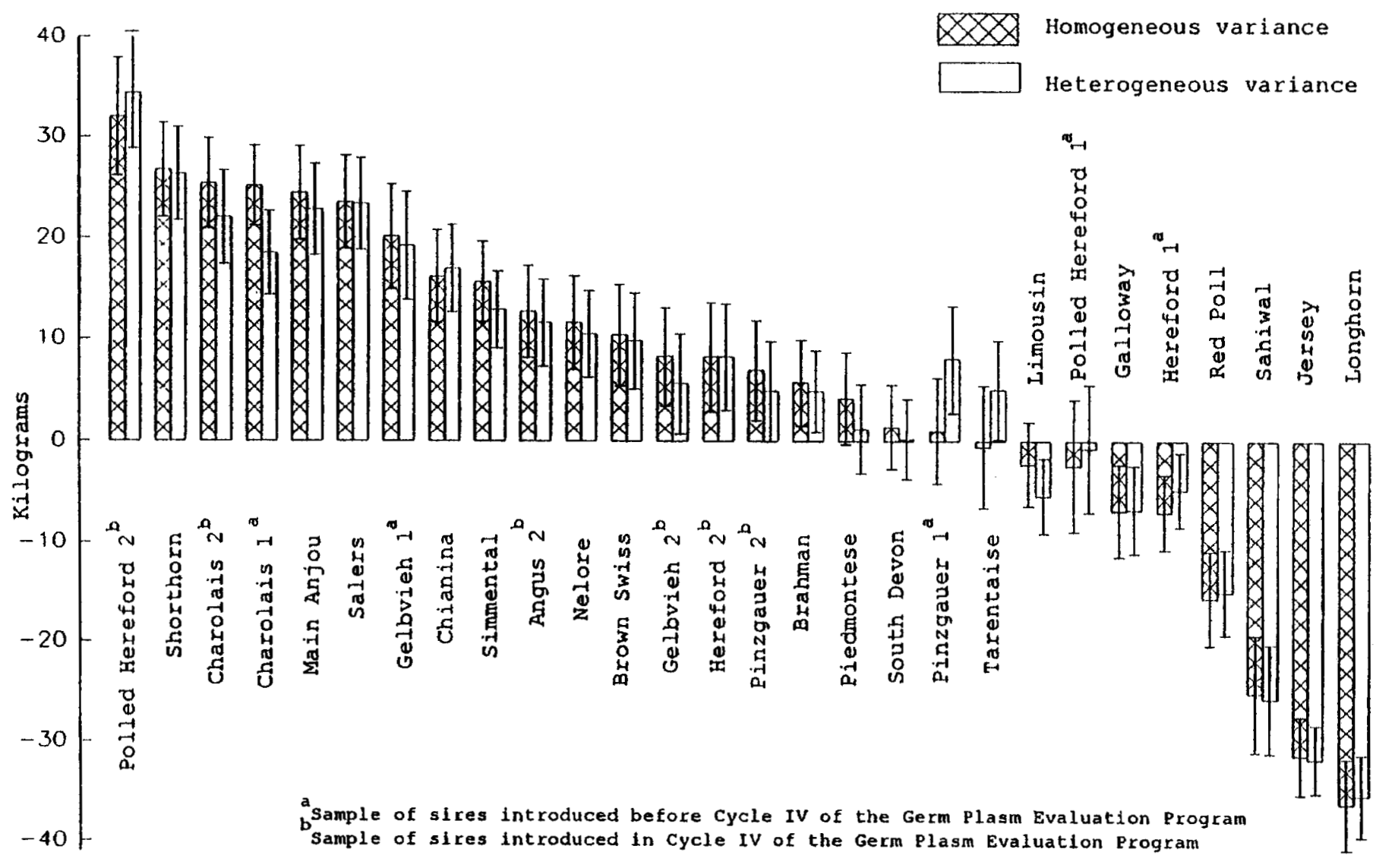

Figure 2. Estimates of breed of sire effects $( \pm \mathrm{SE}$ ), as deviations from Angus 1a, for 365-d weight with models assuming 1) homogeneous or 2) heterogeneous variances.

progeny of matings of Hereford and Angus cows to sires of 23 breeds). With purebreds the ranges in scaling factors may be larger than the ones observed in the present study.

Pooled estimates of the phenotypic variances across all sire breed-sex subclasses are also given in Table 4. These estimates are 489 and $1,072 \mathrm{~kg}^{2}$ for $\mathrm{WW}$ and YW, respectively. To obtain the estimates of phenotypic variances for each sire breed-sex subclass, the common estimates of phenotypic variances were multiplied by the squares of the corresponding $\lambda_{\mathrm{ij}}$ ratios (Table 3 ) or by the squares of the $\lambda_{i}$ ratios (Table 4) to obtain estimates of the phenotypic variance for each sire breed.

Sire Breed Effects. Estimates of breed of sire effects, as deviations from the first sample of Angus sires (Angus 1), are presented in Figures 1 and 2 for WW and YW, respectively. In general, estimates of sire breed group effects for WW obtained with the model accounting for differences in phenotypic variances (Model II) were not much different from the ones obtained with the model assuming common variances (Model I). The largest differences were for the second sample of Hereford sires and the first sample of
Pinzgauer sires for which the breed group effects estimated with Model II were 3.56 and $3.21 \mathrm{~kg}$, respectively, larger than the ones estimated with Model I; however, these differences correspond to approximately half the standard errors for the respective estimates of the breed group effects (Figure 1). The average of the absolute differences between estimates of the breed group effects for WW for the two models was $1.76 \mathrm{~kg}$.

For YW (Figure 2), the estimates of the breed group effects obtained with Model II for the first sample of Pinzgauer sires and Tarentaise sires were 15.4 and $12.3 \mathrm{~kg}$, respectively, larger than the ones obtained with Model I. For the first sample of Charolais sires this difference was in the opposite direction, with the estimate of the sire breed effect obtained with Model I being $14.7 \mathrm{~kg}$ greater than the one obtained with Model II. These differences were larger than the corresponding standard errors for the estimates of breed group effects but were less than twice the average of the pairs of standard errors for each pair of estimates from both models (Figure 2), which indicates lack of significance of these differences. The average of absolute differences between 
a)

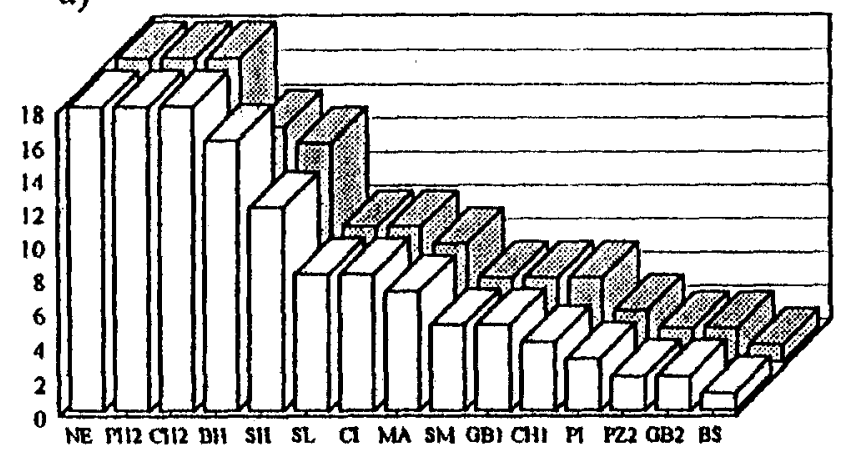

c)

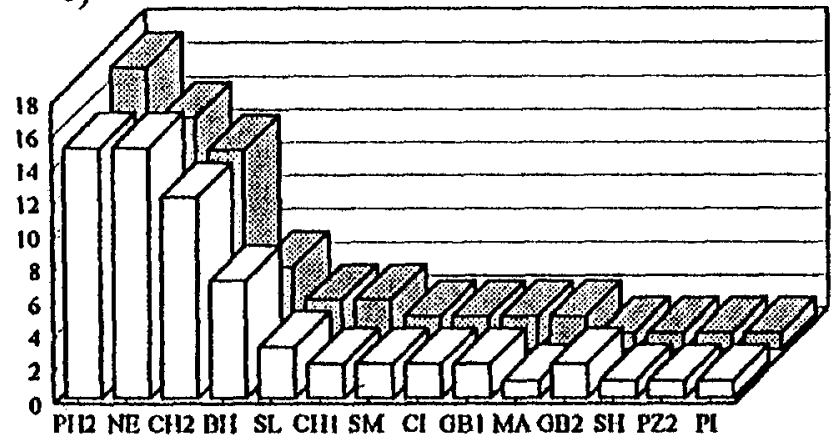

b)

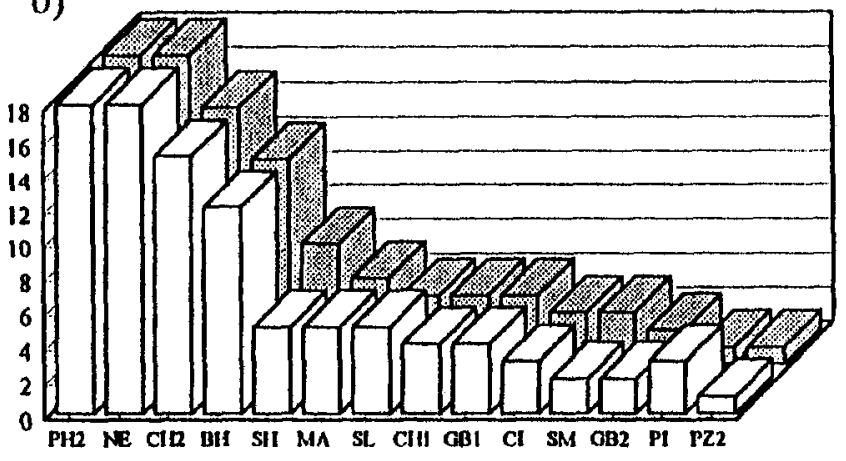

d)

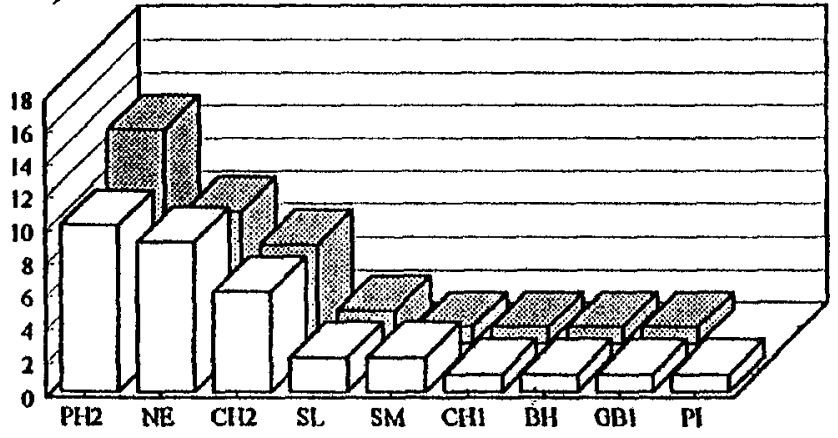

Figure 3. Number of sires selected from the Charolais ( $\mathrm{CH} 1$ and $\mathrm{CH} 2)$, Nelore (NE), Polled Hereford (PH2), Brahman (BH), Shorthorn (SH), Salers (SL), Maine-Anjou (MA), Chianina (CI), Simmental (SM), Piedmontese (PI), Gelbvieh (GB1 and GB2), Pinzgauer (PZ2), and Brown Swiss (BS) breeds, according to their EPD for 200 -d weight when selecting top a) 20 , b) 15 , c) 10 , or d) $5 \%$ with models assuming 1) homogeneous or 2) heterogeneous phenotypic variances.

estimates of breed group effects obtained with the two models for YW was $4.25 \mathrm{~kg}$. Núñez-Domínguez et al. (1995) did not observe significant changes in estimates of sire breed effects for birth weight and weaning weight obtained with animal models accounting for heterogeneous variances as compared to assuming homogeneous variances, but they did observe substantial changes (e.g., $11.1 \mathrm{~kg}$ for Tarentaise and $9.9 \mathrm{~kg}$ for Simmental) in estimates of breed effects for yearling weight.

Ratios of the standard errors for estimates of sire group effects obtained with Model II to the ones obtained with Model I were calculated. Correlations between these ratios and the scaling factors $\left(\lambda_{\mathrm{j}}\right)$ for the sire breeds were .97 and .89 for $\mathrm{WW}$ and $\mathrm{YW}$, respectively.

Comparisons among sire breeds based on estimates of sire genetic group effects as obtained in the present analyses are appropriate only within cycles of the GPE program. Núñez-Domínguez et al. (1993) and Cundiff (1994) presented updates on comparisons among sire breeds based on procedures proposed by Notter and Cundiff (1991) to adjust for sire sampling and genetic trend.
Ranking of Sires. Product-moment and rank correlations across breeds for EPD obtained with Model I and Model II were .99 or larger. These correlations were greater than .93 when computed by breed group. Not much reranking of sires occurred when ranked based on EPD obtained with the two models, although there were some minor changes in the proportions of sires contributed by different breeds to the total of sires selected under different selection intensities (Figures 3 and 4 and Table 5). For example, under $20 \%$ selection intensity (Figure 4a), the Charolais 1 sire group contributed five fewer sires with ranking based on Model II compared to ranking based on Model I. Other breed groups that contributed fewer sires under Model II than under Model I were Charolais 2, MaineAnjou, and Piedmontese. The opposite situation was observed for the Shorthorn, Chianina, Salers, and the second samples of Pinzgauer and Hereford breeds. These breeds all together contributed eight sires more under Model II than under Model I for a selection intensity of 20\% (Table 5). The changes in proportions of selected sires contributed by different breeds were slightly larger for YW than for WW (Table 5). 


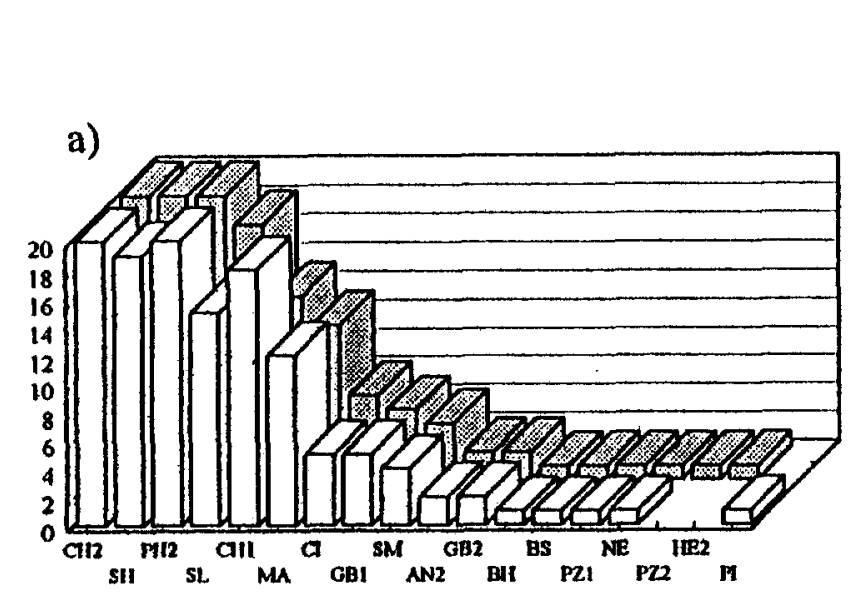

c)

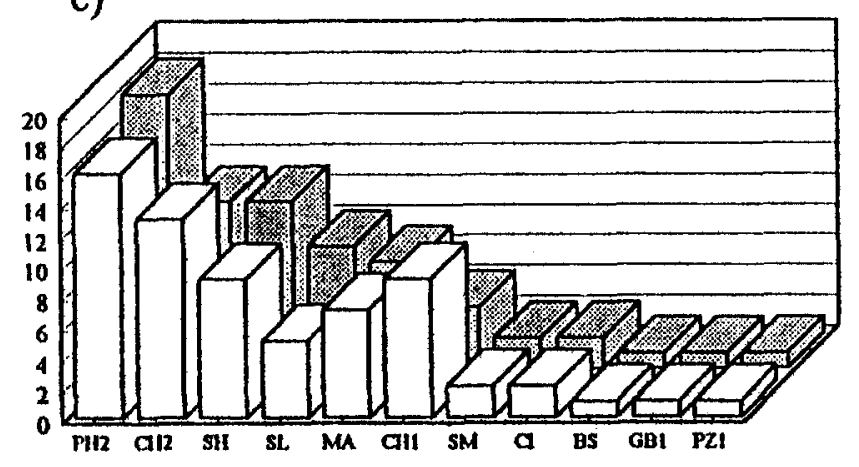

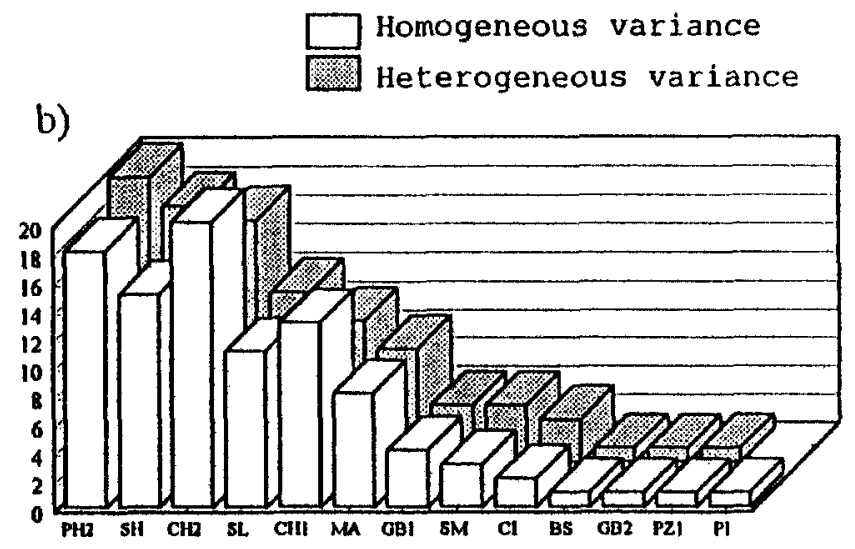

d)

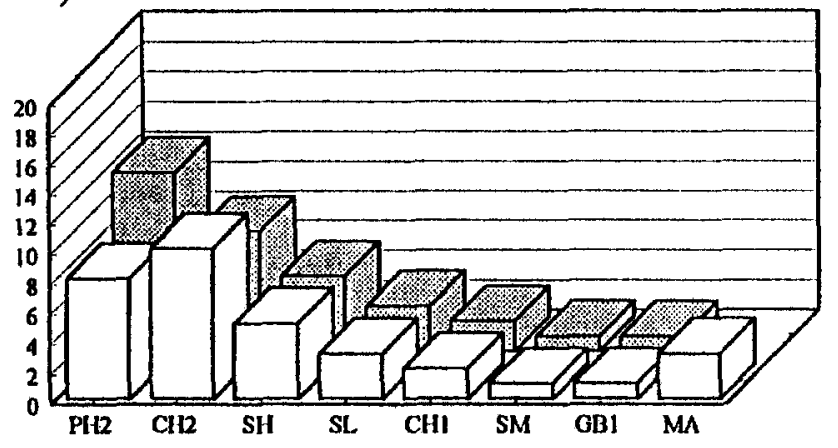

Figure 4. Number of sires selected from the Charolais ( $\mathrm{CH} 1$ and $\mathrm{CH} 2)$, Nelore (NE), Pooled Hereford (PH2), Brahman (BH), Shorthorn (SH), Salers (SL), Maine-Anjou (MA), Chianina (CI), Simmental (SM), Piedmontese (PI), Gelbvieh (GB1 and GB2), Pinzgauer (PZ1 and PZ2), Brown Swiss (BS), Hereford (HE2), and Angus (AN2) breeds, according to their EPD for 365-d weight when selecting top a) 20, b) 15, c) 10, or d) $5 \%$ with models assuming 1) homogeneous or 2) heterogeneous phenotypic variances.

In general, the changes in numbers of sires contributed by the different breeds according to the model used were due to changes in estimates of the breed group effects under the two models (Figures 1 and 2). If the estimate of the breed group effect was larger under Model II than under Model I, that group tended to contribute more sires when the ranking was done with EPD obtained with Model II (Figures 3 and 4).

In spite of changes in the number of sires contributed by the different breeds when selection was based on rankings under the two different models, the means of the expected progeny differences obtained with the more complete model (Model II) did not change substantially for either WW or YW (Table 6). Thus, genetic progress would be similar if selection of sires were made under either model. Núñez-Domínguez et al. (1995) observed a relatively large effect by accounting for heterogeneity of variances according to sire breed on EPD for WW and YW; however, they used a large range of estimated values for variance components as fractions of the phenotypic variance (e.g., the range of heritability estimates was from .18 to .55 for WW and from .15 to .75 for YW for the different sire breeds that they considered). Vinson (1987) argued that heterogeneous variances according to subclasses of fixed effects should not have much effect on genetic progress if the heteroscedasticity was due only to scaling effects and not due to differences in fractions of the variance components, with this last factor having the largest effect on genetic gain.

Assuming homogeneous variances, even if variance components as fractions of phenotypic variances were

Table 5. Numbers of sires from the selected group across breeds that were substituted by sires from different breeds when accounting for differences in phenotypic variances

\begin{tabular}{lcc}
\hline \hline & \multicolumn{2}{c}{ Trait } \\
\cline { 2 - 3 } Selection intensity, \% & 200-d weight & 365-d weight \\
\hline 20 & $2 / 132$ & $8 / 132$ \\
15 & $5 / 99$ & $8 / 99$ \\
10 & $4 / 66$ & $7 / 66$ \\
5 & $3 / 33$ & $5 / 33$ \\
\hline
\end{tabular}


Table 6. Means of expected progeny differences obtained with a model accounting for differences in phenotypic variances (HETVAR) for sires ranked with models using heterogeneous or homogeneous (HOMVAR) variances

\begin{tabular}{lccccc}
\hline \hline \multirow{2}{*}{$\begin{array}{l}\text { Selection } \\
\text { intensity, \% }\end{array}$} & \multicolumn{2}{c}{200 -d weight, kg } & & \multicolumn{2}{c}{365 -d weight, $\mathrm{kg}$} \\
\cline { 2 - 3 } \cline { 5 - 6 } \cline { 5 - 6 } & HOMVAR & HETVAR & & HOMVAR & HETVAR \\
\hline 15 & 16.30 & 16.32 & & 28.78 & 28.88 \\
10 & 17.18 & 17.20 & & 30.80 & 30.96 \\
5 & 18.28 & 18.33 & & 33.52 & 33.76 \\
\hline
\end{tabular}

different across subclasses this should have little effect on estimates of breed effects unless the design is very strange. However, even with the same proportional contributions to phenotypic variance but with different phenotypic variance, differences in ranking of sires across breeds are expected. Larger phenotypic variances will increase the range in sire means, so that the range in the sire means weighted, according to the number of progeny and heritability, will also be greater. Thus, with intense selection, a greater fraction of bulls will be selected from the more variable breeds than from less variable breeds.

In the present study, reranking was not important due to three possible reasons. First, differences in phenotypic variances among sire breeds were not very large (Table 4). Second, differences in means of sire breeds were large (Figures 1 and 2), and because these differences are part of an across-breed EPD, sires from a breed with a large mean are more likely to be selected. In addition, breeds with large means tended to have large phenotypic variances and, therefore, an increased probability of sires with large progeny means. But, because sires from breeds with large means already had large across-breed EPD, compared to sires from breeds with small means, using a larger phenotypic variance in the model for those breeds did not affect ranking. The third possible reason is related to differences in variances due to sex. These differences may affect ranking of sires when records are selectively reported according to sex (Garrick et al., 1989), such that some sires have more information from male progeny than from female progeny. This was not important in the present study (Table 2). Thus, conclusions about reranking from this study are limited to the present situation with $\mathrm{F}_{1}$ calves, non-selectively reported records according to sex, and only two breeds of dam.

Standard Errors of Prediction. The square root of the prediction error variance is defined as the standard error of prediction (SEP). Standard errors of prediction were computed for the sire random effects obtained with Model II and multiplied by the corresponding scaling factors $\left(\lambda_{i}\right)$ according to sire breed. The ratios of those SEP to the SEP for the sire effects predicted with Model I had a correlation of .99 with the $\lambda_{i}$ ratios. A correlation of .99 was also observed for the $\lambda_{i}$ ratios with the ratios of SEP for the EPD obtained with Model II to SEP for the EPD obtained with Model I. Van Vleck (1994) developed procedures to compute SEP for across-breed EPD assuming common variances across sire breeds. The large correlations obtained here, both for ratios of standard errors for estimates of breed effects with $\lambda_{i}$ scaling factors and ratios of SEP for sire effects with $\lambda_{i}$ scaling factors, indicate that it should be straightforward to adjust SEP for across-breed EPD (Van Vleck, 1994) according to differences in phenotypic variances among the different sire breeds. The assumption that is made in this situation is that variance components as fractions of the phenotypic variance are equal across breeds.

\section{Implications}

Some changes in estimates of sire breed effects and in prediction of expected progeny differences occur if differences in phenotypic variances for 200- and 365-d weights according to sire breed and sex are accounted for. However, reranking of sires is minimal. The number of selected sires contributed by different breeds changed slightly when heterogeneous phenotypic variances were considered in the model, but potential genetic gain does not seem to be affected substantially. This may be due to the fact that in the present study data came from a designed experiment with only $F_{1}$ progeny and non-selectively reported records. Results may not be the same for more general situations. Changes in standard errors of prediction for EPD and standard errors for estimates of breed effects are proportional to the ratios of the phenotypic standard deviations of the sire breeds to the common phenotypic standard deviation.

\section{Literature Cited}

Boldman, K. G., L. A. Kriese, L. D. Van Vleck, and S. D. Kachman. 1993. A manual for use of MTDFREML, A set of programs to obtain estimates of variances and covariances. ARS, USDA, Clay Center, NE.

Brotherstone, S., and W. G. Hill. 1986. Heterogeneity of variance amongst herds for milk production. Anim. Prod. 42;297. 
Cundiff, L. V. 1994. Procedures for across breed EPD's. Proc. of the Fourth Genetic Prediction Workshop. Kansas City, MO.

Elzo, M. A. 1990. Recursive procedures to compute the inverse of the multiple trait additive genetic covariance matrix in inbred and noninbred multibreed populations. J. Anim. Sci. 68:1215.

Garrick, D. J., E. J. Pollak, R. L. Quaas, and L. D. Van Vleck. 1989. Variance heterogeneity in direct and maternal weight traits by sex and percent purebred for Simmental-sired calves. J. Anim. Sci. 67:2515.

Gianola, D. 1986. On selection criteria and estimation of parameters when the variance is heterogeneous. Theor. Appl. Genet. 72: 671.

Henderson, C. R. 1984. Linear Models in Animal Breeding. p 439 University of Guelph Press, Guelph, Ontario, Canada.

Hill, W. G. 1984. On selection among groups with heterogeneous variance. Anim. Prod. 39:473.

Kachman, S. D., and R. W. Everett. 1993. A multiplicative mixed model when the variances are heterogeneous. J. Dairy Sci. 76: 859.

Koots, K. R., K. M. Wade, B. W. Kennedy, J.C.M. Dekkers, G. C. Smith, and E. B. Burnside. 1994. Method and effect of adjustment for heterogeneous variance of Holstein conformation traits. J. Dairy Sci. 77:294.

Notter, D. R., and L. V. Cundiff. 1991. Across-breed expected progeny differences: Use of within-breed expected progeny differences to adjust breed evaluations for sire sampling and genetic trend. J. Anim. Sci. 69:4763.

Núñez-Domínguez, R., L. D. Van Vleck, and L. V. Cundiff. 1993. Breed comparisons for growth traits adjusted for within-breed genetic trend using expected progeny differences. J. Anim. Sci. 71:1419.

Núñez-Domínguez, R., L. D. Van Vleck, and L. V. Cundiff. 1995. Prediction of genetic values for growth traits of crossbred cattle using a multivariate animal model with heterogeneous variances. J. Anim. Sci. (In press).

Quaas, R. L., D. J. Garrick, and W. H. McElhenney. 1989. Multiple trait prediction for a type of model with heterogeneous genetic and residual covariance structures. J. Anim. Sci. 67:2529.

Rodríguez-Almeida, F. A., L. D. Van Vleck, and L. V. Cundiff. 1995. Heterogeneity of variance by sire breed, sex, and dam breed in 200 - and 365-d weights of beef cattle from a top cross experiment. J. Anim. Sci. 73:2579.

Van Vleck, L. D. 1994. Prediction error variances for inter-breed EPD's. Proc. of the Fourth Genetic Prediction Workshop, Kansas City, MO.

Vinson, W. E. 1987. Potential bias in genetic evaluations from differences in variation within herds. J. Dairy Sci. 70:2450.

Wiggans, G. R., and P. M. VanRaden. 1991. Method and effect of adjustment for heterogeneous variance. J. Dairy Sci. 74:4350. 